\title{
Brigitte ESTÈVE-BELLEBEAU et Mathieu TOUZEIL-DIVINA (dir.), Laï-Cités(s) et discrimination(s)
}

Paris, L'Harmattan, 2017

\section{Candice Bordes}

\section{(2) OpenEdition}

\section{Journals}

Édition électronique

URL : http://journals.openedition.org/rdr/348

DOI : $10.4000 /$ rdr.348

ISSN : 2534-7462

Éditeur

Presses universitaires de Strasbourg

\section{Édition imprimée}

Date de publication : 6 novembre 2018

Pagination : 176-178

ISBN : 979-10-344-0023-2

ISSN : 2493-8637

\section{Référence électronique}

Candice Bordes, « Brigitte estève-Bellebeau et Mathieu touzell-Divina (dir.), Laï-Cités(s) et discrimination(s) », Revue du droit des religions [En ligne], 6 | 2018, mis en ligne le 25 novembre 2019, consulté le 23 novembre 2020. URL : http://journals.openedition.org/rdr/348 ; DOI : https://doi.org/10.4000/rdr.348

Ce document a été généré automatiquement le 23 novembre 2020. 


\section{Brigitte ESTÈVE-BELLEBEAU et Mathieu TOUZEIL-DIVINA (dir.), Laï-Cités(s) et discrimination(s)}

Paris, L'Harmattan, 2017

\section{Candice Bordes}

\section{RÉFÉRENCE}

Brigitte ESTÈVE-BeLleBEAu et Mathieu TOUZEIL-Divina (dir.), Laï-Cités(s) et discrimination(s), Paris, L'Harmattan, 2017 (Les cahiers de la LCD), 183 p.

1 Cet ouvrage collectif propose d'analyser certaines difficultés posées par le principe de laïcité en France. Deux articles visent plus particulièrement les milieux scolaire et carcéral, des espaces dont le statut spécifique implique une appréhension différenciée du principe de laïcité.

2 En théorie comme en pratique, définir la notion de laïcité demeure complexe. De façon générale, elle suppose une séparation des pouvoirs politique et religieux. L'État ne saurait donc favoriser une religion par rapport à une autre et devrait garantir à tous la liberté de conscience. Néanmoins, Brigitte Estève-Bellebeau et Mathieu Touzeil-Divina soulignent le caractère polysémique et polymorphe de ce principe qui, selon les époques, n'a pas été interprété dans le même esprit. Ce n'est plus d'une laïcité (au singulier) dont il faudrait parler, mais de différents modèles de laïcités (au pluriel) qui existent selon les circonstances, les sociétés et les objectifs défendus. Si l'objectif est de lutter contre les discriminations, il existe plusieurs moyens d'y parvenir, donc plusieurs modèles de laïcité valables. D'ailleurs, le terme même de « laïcité » ne trouve pas de réelle traduction à l'étranger où il est plutôt fait usage du terme «secularism ».

En France, la laïcité s'envisage comme une authentique valeur républicaine. Elle est principalement associée à la loi du 9 décembre 1905 relative à la séparation des Églises 
et de l'État. Alors que l'aspiration première de cette loi était de garantir l'égalité des citoyens au regard de toutes les croyances, il semble qu'elle serve actuellement et paradoxalement de fondement à certaines formes de discriminations. Ainsi, «d'un principe [...] intégrateur, la laïcité devient aujourd'hui un principe qui vise à restreindre la liberté de conscience, à l'opposé de sa conception initiale " (Marik Fetouh, p. 45). Les lois du 15 mars 2004 et du 11 octobre 2010 en sont un exemple probant. Si la première interdit le port de signes à caractère religieux ostentatoires dans les établissements scolaires publics, la seconde interdit la dissimulation du visage dans l'espace public pour des raisons de sécurité. Même si ces dispositions conservent un caractère général, il ne faut pas se tromper sur leurs intentions. Il est vrai que les interrogations semblent se cristalliser sur la religion musulmane (Valérie Orange, p. 29). Plusieurs débats ont d'ailleurs été soulevés sur la question du port du voile, de la burqa ou encore plus récemment du burkini (Mathieu Touzeil-Divina, p. 21).

On considère souvent que la " laïcité-combat » défendue en 1789 ou encore sous la III République face à la religion catholique se serait transformée en une "laïciténeutralité ». Or, "aujourd'hui, apparaît une religion revendicatrice et forte, comme l'était le catholicisme au début du xxe siècle. C'est l'islam » (Jacques Viguier, p. 84). Dès lors, serait-il pertinent de revenir à une forme plus active de la laïcité ? À travers sa jurisprudence, le Conseil d'État se fait plutôt le défenseur d'une "laïcité apaisée " (Alexandre Ciaudo, p. 70). Compromis et aménagements sont donc permis dans la limite $\mathrm{du}$ raisonnable et toujours dans le respect de l'ordre public.

5 La loi de 1905 trouve ainsi différentes interprétations, notamment parce que la coordination des deux premiers articles de la loi n'est pas limpide. Entre distanciation ou intervention, il reste difficile pour l'État de conserver toute sa neutralité. Une fois le principe de laïcité appliqué à des espaces tels que l'école ou les établissements pénitentiaires, d'autres obstacles sont à surmonter. Appréhender et faire assimiler le principe de laïcité en classe n'est pas une démarche évidente. Comment la présenter aux élèves? Est-il plus opportun de l'envisager comme une valeur ou comme une norme juridique pour qu'elle soit mieux intégrée? En matière d'éducation, Vincent Lorius estime qu'il faut «abandonner des objectifs de nature morale (qui consistent à respecter des valeurs) pour d'autres qui sont juridiques (qui consistent à respecter des règles)»(p.101). La clarté des règles devrait pouvoir dépasser l'instabilité et la relativité des valeurs, elle devrait apporter une certaine rigueur.

6 Dans le milieu carcéral, d'autres difficultés apparaissent. Il faut prendre en compte le statut particulier de la personne incarcérée, privée de sa liberté d'aller et venir. La détention même de l'individu implique que «l'État est [...] soumis à un ensemble d'obligations positives malmenant le principe de laïcité, afin de rendre effectif le droit à la liberté de religion » (Julia Schmitz, p. 116). Cela se traduit par l'aménagement de sites cultuels ou la prise en compte des régimes alimentaires liés aux différentes pratiques religieuses. Évidemment, l'ensemble de ces aménagements doivent respecter les contraintes que le milieu carcéral impose. Face aux inégalités d'application dont il fait l'objet sur le territoire national et dans un contexte marqué par le terrorisme, le principe de laïcité peut se transformer en véritable problème plus qu'en solution. Malgré tout, il ne faut pas en prononcer l'obsolescence anticipée. Anne Rinert relève justement que «le principe de laïcité, loin d'être caduc, [...] doit être sans cesse (ré)expliqué »(p. 128). 


\section{AUTEURS}

\section{CANDICE BORDES}

Allocataire de recherche en droit public, Université de Perpignan Via Domitia, Centre du droit économique et du développement (CDED) 